\title{
Models for residential indoor pollution loads due to material emissions under dynamic temperature and humidity conditions
}

\author{
Carsten Rode ${ }^{1, *}$, John Grunewald ${ }^{2}$, Zhenlei Liu $^{3}$, Menghao Qin ${ }^{1}$, and Jianshun Zhang ${ }^{3}$ \\ ${ }^{1}$ Technical University of Denmark, Department of Civil Engineering, 2800 Kgs. Lyngby, Denmark \\ ${ }^{2}$ Dresden University of Technology, Institute of Building Climatology, 01069 Dresden, Germany \\ ${ }^{3}$ Syracuse University, Department of Mechanical and Aerospace Engineering, Syracuse, NY 13244, USA
}

\begin{abstract}
The IEA EBC Annex 68 project on "Indoor Air Quality Design and Control in Low Energy Residential Buildings" has been recently completed. The project considered indoor air pollution loads in dwellings, particularly how such pollutants are emitted in dependency of the hygrothermal conditions: temperature, moisture and air flows. Thus, a proper understanding of the mutual interactions between hygrothermal conditions and pollutants was needed to obtain optimal paradigms for demand-controlled ventilation. The project adopted a similarity approach for modelling the transports of moisture and volatile organic compounds (VOCs) in materials, and thereby it was possible to provide a comprehensive set of data and tools whereby the indoor atmospheric conditions of buildings can be optimized, e.g. with respect to the need for ventilation. The paper explains the experimental and modelling approach and presents a summary of the results.
\end{abstract}

\section{On IEA EBC Annex 68}

Following a one-year preparation phase, the working phase of the Annex 68 project was started in 2016 as a project under the Energy in Buildings and Communities (EBC) Technology Collaboration Programme of the International Energy Agency (IEA). The working phase was completed in summer 2019, and final reports of the Annex activities have been produced subsequently.

The project was organized in five subtasks as follows:

Subtask 1, "Defining the metrics", made a literature review of pollutant studies of indoor air quality (IAQ), and proposed a set of performance metrics with respect to IAQ and energy use. The work is reported in [1].

Subtask 2, "Pollutant loads in residential buildings", made mechanistic emission source and sink models for pollution loads under various hygrothermal conditions and developed new data for a database on emission and transport properties for use in models.

Subtask 3, "Modelling - review, gap analysis and categorization", made a classification of available modelling tools and carried out a gap analysis of what is needed for integrated design of low energy and high IAQ buildings. The subtask gathered reference cases with focus on building energy performance under high IAQ conditions.

Subtask 4, "Strategies for design and control of buildings", carried out stakeholder analyses with interviews to develop a guide and collection of cases on operational strategies for optimal energy performance and high IAQ in residential buildings.
Subtask 5, "Field measurements and case studies", explained measurement technologies, made new experiments and gathered case studies to analyse and demonstrate residential buildings where IAQ factors have been documented together with an optimal energy use.

While the final report from Subtask 1 was completed in 2017, the reports from the other subtasks are in review as of writing of this paper (spring 2020) and will eventually be available through the project homepage www.iea-ebc-annex68.org. Reference is made to the final reports for further information on the underlying research questions and explanation of the experimental conditions.

This paper will focus on results from Subtask 2 and 3 - particularly how hygrothermal conditions and building physics theory relates to the study on gaseous emissions.

\section{Similarity approach}

The Annex 68 project was conceived based on the IEA ECBCS Annex 41 project on "Whole Building Heat, Air and Moisture Response" (2003-07) [2], which on a room and whole building level clarified the interaction between the hygrothermal conditions of room air and materials. Such interaction is also at scope when emission (and absorption) of volatile organic compounds (VOCs), such as from materials into indoor environments is studied. Annex 41 stimulated the development of simulation tools that considered the heat, air and moisture (HAM) interactions between rooms and materials. Even though the object parameters are different between the HAM flows and those for flow and retention of organic compounds, there are similarities in the physics, which

\footnotetext{
${ }^{*}$ Corresponding author: car@byg.dtu.dk
} 
could be utilised in modelling. Furthermore, the hygrothermal conditions studied in Annex 41 will also influence on the emissions of VOCs from materials, which further emphasizes why HAM and VOC transport models could benefit from being based on similar platforms.

Another predecessor to Annex 68 has been the socalled "CHAMPS" collaboration, which since 2004 has arranged annular workshop on "Combined Heat, Air, Moisture and Pollutants Simulation" for researchers and students having a background in building physics or indoor chemistry with the purpose exactly to jointly develop and make benefit from the similar approaches and interactions in modelling the phenomena [3].

The remaining parts of this section will further elaborate on the physics of the similarities between transport models for moisture and VOC flow.

\subsection{Similarity in diffusion models}

Different approaches (versions of Fick's law) can be found in literature to model mass diffusion of a component $x$ in a gas phase. Thermodynamic considerations [1], [2], [3] lead to the conclusion that the root driving force of mass diffusion is the gradient of the chemical potential $\nabla \mu_{c h, X}\left(p_{x}, p_{g}, T\right)_{T=\text { const }}$ of the mass component at constant temperature. Processes called "diffusion-thermic" and "thermo-diffusion" are already neglected at this stage.

The gradient of the chemical potential can be split into two independent driving forces, the partial pressure gradient $\nabla p_{X}$ of the mass component $x$ and the total pressure gradient $\nabla p_{g}$ of the gas phase.

$$
\nabla \mu_{c h, x}\left(p_{x}, p_{g}, T\right)_{T=c o n s t}=\underbrace{\frac{\partial \mu_{c h, x}}{\partial p_{x}} \nabla p_{x}}_{\text {normal diffusion }}+\underbrace{\frac{\partial \mu_{c h, v}}{\partial p_{g}} \nabla p_{g}}_{\text {pressure diffusion }}
$$

where

$$
\begin{array}{ll}
p_{x} & \text { Partial pressure of the component } x, \mathrm{~Pa} \\
p_{g} & \text { Total pressure of the gas phase, } \mathrm{Pa}
\end{array}
$$

The second term on the right hand side in Eq. (1) is the pressure diffusion that is considered part of the convective flux of $x$. With the first term on the right hand side in Eq. (1), a generally valid Fick's law (2) can be established.

$$
j_{\text {diff }}^{x}=-K_{x} \cdot \nabla p_{x}
$$

where

$$
\begin{array}{ll}
j_{d i f f}^{x} \quad \text { Diffusive flux of the component } x, \mathrm{~kg} / \mathrm{m}^{2} \mathrm{~s} \\
K_{x} \quad \text { Vapour conductivity of the component } x, \mathrm{~s}
\end{array}
$$

Water vapour diffusion coefficients are usually defined in building physics to describe diffusion processes. Using the partial pressure gradient of water vapour and the general gas law, the respective equation would read as Eq. (3).

$$
j_{\text {diff }}^{v}=-\frac{D_{v, a i r}(T)}{\mu_{v} R_{v} T} \cdot f\left(\theta_{l}\right) \cdot \nabla p_{v}
$$

$D_{v, \text { air }}(T)$ is the diffusion coefficient of water vapour in still air and $\mu_{v}$ is the vapour diffusion resistance factor that accounts for the effects of porosity and tortuosity of the materials. With the volumetric liquid water content $\theta_{l}$, the function $f\left(\theta_{l}\right)$ models the effects of blocking of pores by liquid water and diffusion "shortcuts" created by liquid islands. According to [4], the diffusion coefficient of water vapour in free air depends on temperature but the factor $D_{v, \text { air }}(T) / T$ is almost constant. Consequently the vapour conductivity (4) with two parameters $\mu_{v}$ and $f\left(\theta_{l}\right)$ can be modelled as only-moisture dependent function.

$$
K_{v}\left(\theta_{l}\right)=\frac{D_{v, a i r}(T)}{\mu_{v} R_{v} T} \cdot f\left(\theta_{l}\right)
$$

$$
f\left(\theta_{l}\right)=\left(\theta_{e f f}-\theta_{l}\right) / \theta_{e f f}
$$

Eq. (4) defines the water vapour conductivity $K_{v}\left(\theta_{l}\right)$, which is a direct input to the material files of the CHAMPS-BES / DELPHIN6 software [5] with the vapour diffusion resistance factor $\mu_{v}$ as only remaining parameter. Neglecting the diffusion "shortcuts" created by liquid islands leads to the simplest approach (5) that just accounts for blocking of pores, which is the "default" case implemented in CHAMPS-BES / DELPHIN6.

A similar approach can be applied to the diffusion of pollutants (VOC) in the gas phase of materials. If there exists an equilibrium condition between the VOC concentration in the pore air and the VOC concentration adsorbed in the material, either the gradients 1) of the absorbed VOC concentration in the material or 2) of the VOC concentration in the pore air can be used to calculate the diffusive flux. Accordingly, two different diffusion coefficients are introduced in Eq. (6).

$$
j_{\text {diff }}^{v o c}=-D_{m} \nabla C_{m}=-D_{e} \nabla C_{a}
$$

where

$j_{\text {diff }}^{v o c}$ Diffusive flux of the VOC, $\mathrm{kg} / \mathrm{m}^{2} \mathrm{~s}$

$D_{m}$ Diffusivity of VOC in material, $\mathrm{m}^{2} / \mathrm{s}$

$C_{m}{ }_{m}$ Total mass of VOC per volume of material, $\mathrm{kg} / \mathrm{m}^{3}$

$D_{e} \quad$ Effective Diffusivity of VOC in pore air, $\mathrm{m}^{2} / \mathrm{s}$

$C_{a}^{e}$ Mass of VOC per volume of pore air, $\mathrm{kg} / \mathrm{m}^{3}$

While Eq. (6) is valid in case of isothermal problems, an additional temperature dependent term has to be considered for non-isothermal problems (7).

$$
\nabla p_{v o c}=R_{v o c} T \cdot \nabla C_{a}+\underbrace{C_{a} R_{v o c} \cdot \nabla T}_{=0 \text { in isothermal conditions }}
$$

where

$$
\begin{array}{ll}
p_{v o c} & \text { Partial pressure of VOC, } \mathrm{Pa} \\
T & \text { Temperature, K } \\
R_{v o c} & \text { Specific gas constant of VOC, } \mathrm{J} / \mathrm{kgK}
\end{array}
$$


In order to create a model being generally valid under non-isothermal and non-isobaric conditions, the diffusion Eq. (8) and the convection Eq. (9) have been implemented in the CHAMPS-BES / DELPHIN6 software. The splitting of the gradient of the chemical potential into gradients of the partial and the total pressure according to Eq. (1) enables the simulation of VOC transport processes, even when air convection takes place.

$$
\begin{gathered}
j_{d i f f}^{v o c}=-K_{v o c} \nabla p_{v o c}=-\frac{D_{v o c, a i r}(T)}{\mu_{v o c} R_{v o c} T} \nabla p_{v o c} \\
j_{c o n v}^{v o c}=C_{a} \cdot v_{c o n v}^{g}
\end{gathered}
$$

where

$\begin{array}{ll}j_{\text {diff }}^{\text {voc }} & \text { Diffusive flux of the VOC, } \mathrm{kg} / \mathrm{m}^{2} \mathrm{~s} \\ j_{\text {von }}^{\text {voc }} & \text { Convective flux of the VOC, } \mathrm{kg} / \mathrm{m}^{2} \mathrm{~s} \\ v_{\text {conv }}^{g} & \text { Volumetric flux of the gas phase, } \mathrm{m}^{3} / \mathrm{m}^{2} \mathrm{~s} \\ p_{\text {VOC }} & \text { Partial pressure of the VOC }, \mathrm{Pa} \\ D_{\text {voc,air }} & \text { Diffusion coefficient in still air, } \mathrm{m}^{2} / \mathrm{s} \\ T & \text { Absolute Temperature, K } \\ R_{\text {voc }} & \text { Specific gas constant of VOC, } \mathrm{J} / \mathrm{kgK}\end{array}$

Fortunately, there is no problem using the diffusion coefficients determined under isothermal conditions for calculations under non-isothermal conditions.

The diffusivity of VOC in a material can be found from the diffusivity of the VOC in atmospheric air:

$$
D_{e}=\frac{\varepsilon}{\tau} D_{v o c, a i r}=\frac{D_{v o c, a i r}}{\mu_{v o c}}
$$

where

$$
\begin{array}{ll}
\varepsilon & \text { Porosity of material, - } \\
\tau & \text { Tortuosity of the material's pore system, }- \\
\mu_{\text {voc }} & \text { Diffusion resistance factor of VOC, - }
\end{array}
$$

The bimolecular diffusion coefficient of water vapour or a VOC in air can be calculated as follows [6]:

$$
D_{\text {voc, air }}(T)=\frac{10^{-7} T^{1.75}\left(\frac{1}{M_{A i r}}+\frac{1}{M_{B}}\right)^{0.5}}{P_{\text {atm }}\left(V_{\text {Air }}^{\frac{1}{3}}+V_{B}^{\frac{1}{3}}\right)^{2}}
$$

where

$$
\begin{array}{ll}
M_{A i r} & \text { Molecular weight of atmosph. air, } 28.96 \mathrm{~g} / \mathrm{mol} \\
M_{B} & \text { Molecular weight of gaseous compound, g/mol } \\
P_{\text {atm }} & \text { Atmospheric pressure, atm } \\
V_{A i r} & \text { Diffusion volume of dry air, } 19.7 \\
V_{B} & \text { Diffusion volume of gaseous compound, - }
\end{array}
$$

The diffusion volume of gaseous compound $B$ can be found as the sum of the diffusion volumes of all the atoms it consists of [6]: 15.9 for $\mathrm{C}, 2.31$ for $\mathrm{H}, 6.11$ for $\mathrm{O}$, and 4.54 for N. 18.3 should be subtracted from the diffusion volume of molecules that contain aromatic or heterocyclic rings. The diffusion volume has been measured particularly for the following common molecules: 18.5 for $\mathrm{N}_{2}, 16.3$ for $\mathrm{O}_{2}, 13.1$ for $\mathrm{H}_{2} \mathrm{O}$ and 19.7 for atmospheric air.

Fig. 1 shows how the VOC diffusivity in air at reference temperature, $D_{v o c, a i r}\left(T_{r e f}\right)$, varies the with molar mass of the VOC. From evaluation of Eq. (11), it can be concluded that the diffusion speed at given pressure difference decreases with higher molar mass. All data points depicted in Fig. 1 follow a natural logarithm law as shown by the trend equation.

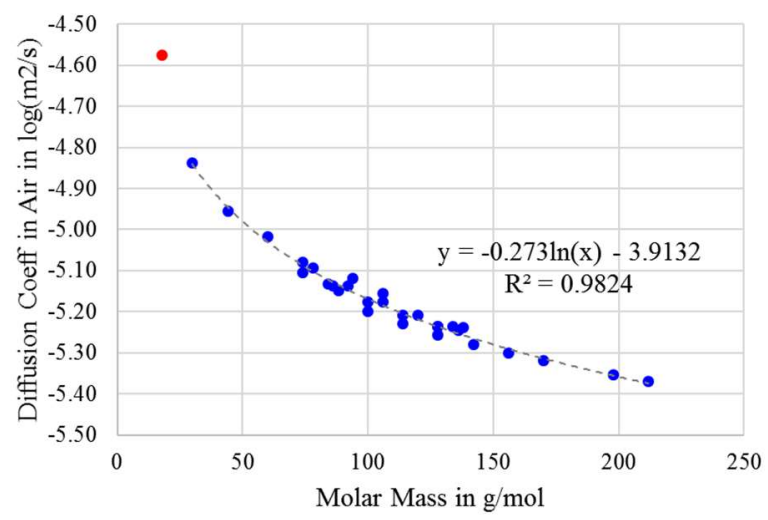

Fig. 1. Diffusion coefficients of VOCs (blue) and water vapour (red) in air at $23^{\circ} \mathrm{C}$ as function of molar mass.

Eq. (11) also indicates how the temperature has a clear influence on the diffusivity, since it is proportional with the absolute temperature raised to the power 1.75.

Since not much data exist on VOC diffusion and retention properties of building materials, a similarity approach, Eq. (12), has been introduced to make it possible to predict these coefficients from moisture transport properties. When $\mu$ is known both for a particular VOC and also for water vapour, a diffusion similarity factor $\kappa_{\text {diff, voc }}$ can be defined as follows:

$$
\kappa_{\text {diff }, v o c}=\frac{\mu_{v o c}}{\mu_{v}}
$$

Given the same gradients of partial pressures, a diffusion similarity factor of 1 would mean that the VOC molecules diffuse at the same rate as water vapour molecules. In reality, the diffusion similarity factor in Eq. (12) is expected to have values that differ from 1. It probably depends on the physical / chemical properties of the VOC molecules.

\subsection{Similarity in retention models}

An equilibrium exists between the concentration of VOC being absorbed in a material, $C_{m}$, and the concentration in its pore air, $C_{a}$. The equilibrium concentrations change proportionally with one another, as described by the socalled partition coefficient, $K_{m a}$ (with the assumption that the equilibrium is achieved instantaneously or in effect much faster than the diffusion):

$$
C_{m}=K_{m a} C_{a}
$$

With this definition and Eq. (6), also a relationship between the diffusivity of a gaseous compound in a material and in air can be set up:

$$
D_{e}=K_{m a} D_{m}
$$


Table 1 shows the molecular weight, partition coefficient and diffusivity, $D_{m}$, of various VOCs in a material such as particleboard. Fig. 2 shows graphically how VOC diffusivity, $D_{m}$, in particleboard varies with molar mass of the VOC.

Table 1. Molecular weight, partition coefficient and Diffusivity of various VOCs in particleboard.

\begin{tabular}{|l|r|r|r|}
\hline VOC & $\begin{array}{r}\text { Mol. weight } \\
\text { g/mol }\end{array}$ & $\boldsymbol{K}_{\boldsymbol{m a}}$ & $\begin{array}{r}\boldsymbol{D}_{\boldsymbol{m}} \\
\mathbf{m}^{2} \mathbf{s}\end{array}$ \\
\hline Acetaldehyde & 44.05 & 17,300 & $1.67 \cdot 10^{-11}$ \\
\hline Acrolein & 56.06 & 627 & $5.16 \cdot 10^{-08}$ \\
\hline Alpha-pinene & 136.23 & 1,740 & $1.74 \cdot 10^{-10}$ \\
\hline Benzene & 78.11 & 266 & $7.33 \cdot 10^{-10}$ \\
\hline Formaldehyde & 30.03 & 2,940 & $4.84 \cdot 10^{-10}$ \\
\hline Naphthalene & 128.17 & 263,000 & $2.39 \cdot 10^{-11}$ \\
\hline Styrene & 104.15 & 1,210 & $1.00 \cdot 10^{-10}$ \\
\hline Toluene & 92.14 & 968 & $2.68 \cdot 10^{-10}$ \\
\hline
\end{tabular}

VOCs $\neq$ Aromatic hydrocarbon - Aldehyde

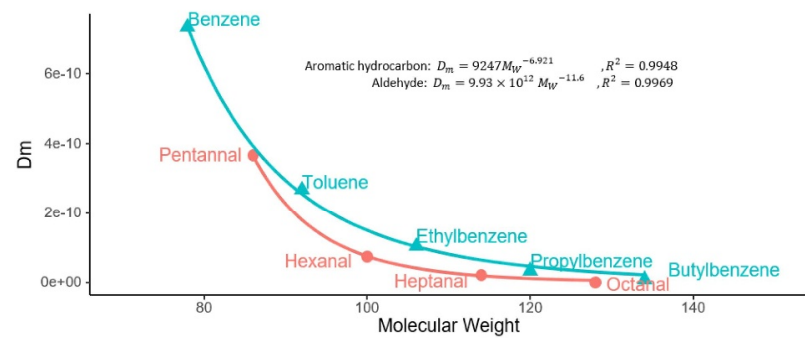

Fig. 2. Diffusivity, $D_{m}$, in particleboard of various VOCs in dependency of their molecular weight. [12]

The most related counterpart in moisture physics to the partition coefficient is the sorption curve that describes the relationship between the volumetric moisture content in a material, $\theta_{l}, \mathrm{~m}^{3}{ }_{\mathrm{H} 20} / \mathrm{m}^{3}$ mat on the sorption curve's ordinate axis, and relative humidity, $\varphi,-$, in pore air on the abscissa axis. Relative humidity is equal to the partial pressure of water vapour in air, $p_{v}, \mathrm{~Pa}$, divided by its saturation value, $p_{v, \text { sat }}(T)$ :

$$
\varphi=\frac{p_{v}}{p_{v, s a t}(T)}
$$

The slope of the sorption curve (at constant temperature) is the specific moisture capacity, $\xi$, $\mathrm{m}^{3} \mathrm{H} 20 / \mathrm{m}^{3}$ mat, at a given relative humidity:

$$
\xi=\frac{\partial \theta_{l}}{\partial \varphi}
$$

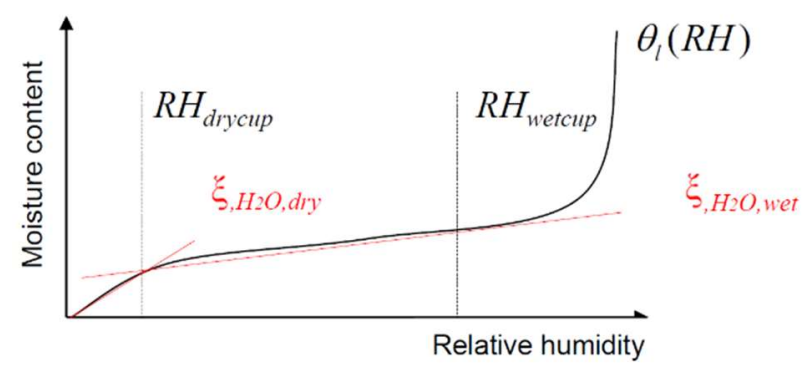

Fig. 3. Sorption curve, where the specific moisture capacity $=$ slope of the curve represents a partition coefficient for moisture.
Similarly to Eq. (13), a "partition coefficient" for moisture, $K_{m a, H 2 O}$, of a hygroscopic material can be introduced by relating gradients of the absorbed moisture content mass by volume of material, $w, \mathrm{~kg}_{\text {absorbed } \mathrm{H} 20} / \mathrm{m}^{3}$ mat, to gradients of the humidity of air by volume of the pores, $v, \mathrm{~kg}_{\mathrm{H} 20 \text { vapour }} / \mathrm{m}^{3}$ pore, at equilibrium condition:

$$
K_{m a, H_{2} O}=\frac{\partial w}{\partial v}=\frac{\rho_{l} \partial \theta_{l}}{\frac{1}{R_{v} T} \partial p_{v}}=\frac{\rho_{l} R_{v} T}{p_{v, s a t}(T)} \xi
$$

where

$\rho$ Density of water, $\mathrm{kg} / \mathrm{m}^{3}$

$R_{v}$ Gas constant for water vapour $=461.5 \mathrm{~J} /(\mathrm{kg} \cdot \mathrm{K})$

As can be seen from Fig. 3, $\xi$ has a significant variation over the relative humidity $(\mathrm{RH})$ range. The first steep range from $\varphi=0$ to about $20 \% \mathrm{RH}$ may be most appropriate to serve as a proxy for VOC-sorption, since VOCs typically deposit in monolayers, like the initial low-RH sorption of water vapour. Thus, the partition coefficient of water according to Eq. (17) should be calculated based on the specific moisture capacity from the initial driest range of the sorption curve. Since the saturation vapour pressure in the denominator is strongly temperature dependent, it should be mentioned that the derivation assumes isothermal conditions.

With $a$ and $b$ being empirically determined coefficients, $\mathrm{K}_{\mathrm{ma}, \mathrm{H} 2 \mathrm{O}}$ can be used as a reference to estimate $K_{m a, v o c}$ of a VOC assuming a power-law relationship between a partition coefficient and its vapour pressure, $p_{\text {vapour }}[12]$ (e.g. water vapour or a VOC):

$$
K_{m a}=a \cdot p_{\text {vapour }}^{-b}
$$

The coefficient $b$ ranged from 0.9 to 1.2 for aromatic hydrocarbon in gypsum board [12]. With $b=1$, a partition similarity coefficient $\kappa_{\text {part, voc }}=a_{v o c} / a_{v}$, can be introduced as:

$$
\frac{K_{m a, v o c}}{K_{m a, H_{2} O}}=\frac{a_{v o c}}{a_{v}} \frac{p_{v, s a t}\left(T_{r e f}\right)}{p_{v o c, s a t}\left(T_{r e f}\right)}
$$

The partition similarity coefficient $\kappa_{\text {part,voc }}$ depends on material properties and VOC properties. Table 2 presents its variation over different VOCs. Further studies are to be carried out to examine these dependencies.

Table 2. Vapour pressure, partition coefficient, and partition similarity coefficient of various VOCs in calcium silicate

\begin{tabular}{|l|r|r|r|}
\hline VOC & $\begin{array}{r}\text { Vapour } \\
\text { pressure } \\
\text { mmHg }\end{array}$ & $\boldsymbol{K}_{\boldsymbol{m a} \boldsymbol{\text { , voc }}}$ & $\begin{array}{r}\text { Partition } \\
\text { similarity } \\
\text { coefficient }\end{array}$ \\
\hline toluene & 25.8 & 133 & 0.3598 \\
\hline acetaldehyde & 837.5 & 221 & 19.41 \\
\hline hexanal & 10 & 7,809 & 8.189 \\
\hline benzene & 1.06 & 16,111 & 1.791 \\
\hline butanol & 6.5 & 18,100 & 12.34 \\
\hline formaldehyde & 3643.8 & 2,597 & 992.4 \\
\hline
\end{tabular}




\section{Effects of temperature and relative humidity}

Next, we will briefly show some results of temperature and humidity effects on emission of formaldehyde in a an ASTM standard small emission test chamber. Three series of experiments S1-S3 were conducted with four cases in each. Each series was carried out by keeping either the temperature $(t)$, the absolute humidity $(\mathrm{AH})$ or the relative humidity $(\mathrm{RH})$ the same when the other parameters varied between the cases. Experimental parameter settings of each case are specified in Table 2.

Fig. 4 illustrates the measurement results of different humidity scenarios when the temperature was kept the same $\left(25.5^{\circ} \mathrm{C}\right)$. Formaldehyde concentrations increased to a peak value in the first few hours and then decreased slightly. Remarkable differences occurred between the cases. Formaldehyde concentrations in the air of the chamber were higher at the high humidity scenarios, suggesting a stimulating effect of humidity on formaldehyde emissions. More specifically, chamber concentrations at the $\mathrm{RH}-$ level of $80 \%\left(\mathrm{AH}=16.7 \mathrm{~g} / \mathrm{kg}_{\text {air }}\right)$ were about three times higher than at $\mathrm{RH}=20 \%(\mathrm{AH}=$ $\left.4.0 \mathrm{~g} / \mathrm{kg}_{\text {air }}\right)$ at the same emission time. Despite the differences in concentration levels, the general trend in variation over these four scenarios were similar.

Measurement of formaldehyde concentrations in the series S2 and S3 are shown in Fig. 5 (a) and (b). The effect of temperature could be discussed with results from series S2 when absolute humidity was kept the same and temperature, but consequently also RH since, varied. The combined effect of temperature and absolute humidity could be discussed with results from series S3 when $\mathrm{RH}$ was kept the same between the cases. Although the temperature effect could not be studied in isolation without affecting one of the humidity parameters, $\mathrm{RH}$ or $\mathrm{AH}$, the formaldehyde concentration always increased with temperature (Fig. 5 (a) and (b)). A qualitative conclusion about the stimulating effect of temperature on formaldehyde emission is consistent with that reported in literature from a traditional approach of study where $\mathrm{RH}$ is kept constant.

Table 2. Environmental parameter settings based on ventilated environmental chambers at different scenarios.

\begin{tabular}{llll}
\hline $\begin{array}{l}\text { Series } \\
\text { No. }\end{array}$ & $\begin{array}{l}\text { Temperature, } \boldsymbol{t} \\
\left({ }^{\circ} \mathbf{C}\right)\end{array}$ & $\begin{array}{l}\text { Relative } \\
\text { humidity, } \\
\text { RH (\%) }\end{array}$ & $\begin{array}{l}\text { Absolute } \\
\text { humidity, } \\
\mathbf{A H}(\mathbf{g} / \mathbf{k g} \text { air })\end{array}$ \\
\hline \multirow{3}{*}{ S1 } & $25.5 \pm 0.5$ & $20 \pm 5$ & $4.0 \pm 0.5$ \\
& $25.5 \pm 0.5$ & $30 \pm 5$ & $6.1 \pm 0.5$ \\
& $25.5 \pm 0.5$ & $50 \pm 5$ & $10.4 \pm 0.5$ \\
& $25.5 \pm 0.5$ & $80 \pm 5$ & $16.7 \pm 0.5$ \\
\hline \multirow{4}{*}{ S2 } & $7.0 \pm 0.5$ & $62.0 \pm 5$ & $4.0 \pm 0.5$ \\
& $15.0 \pm 0.5$ & $38.6 \pm 5$ & $4.0 \pm 0.5$ \\
& $25.5 \pm 0.5$ & $20.0 \pm 5$ & $4.0 \pm 0.5$ \\
& $34.1 \pm 0.5$ & $12.0 \pm 5$ & $4.0 \pm 0.5$ \\
\hline \multirow{3}{*}{ S3 } & $5.2 \pm 0.5$ & $50.0 \pm 5$ & $2.8 \pm 0.5$ \\
& $15.0 \pm 0.5$ & $50.0 \pm 5$ & $5.2 \pm 0.5$ \\
& $25.5 \pm 0.5$ & $50.0 \pm 5$ & $10.4 \pm 0.5$ \\
& $35.0 \pm 0.5$ & $50.0 \pm 5$ & $17.8 \pm 0.5$ \\
\hline
\end{tabular}

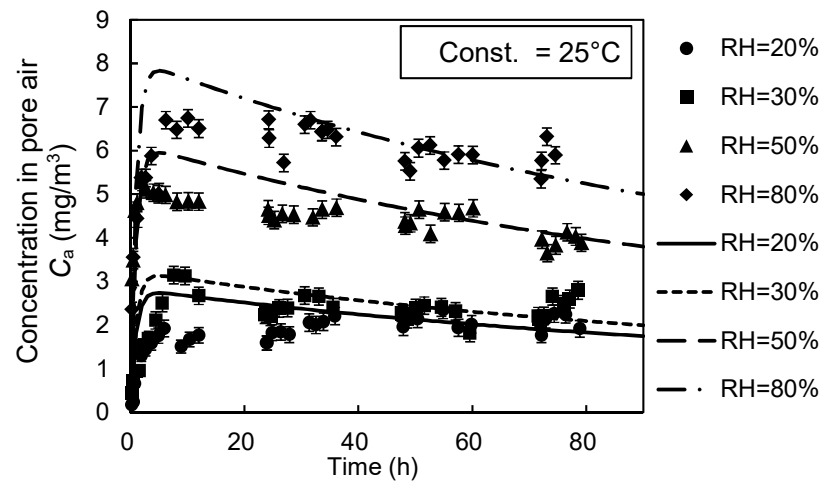

Fig. 4. Time-varying formaldehyde concentrations in the air of the chamber at different humidity levels. Dots represent the measured data and lines represent the regression curves. Error bars are the estimated measurement errors.

The qualitative conclusion about the effect of temperature on formaldehyde concentration becomes the same for these two different approaches. However, concentration differences when relative humidity was kept always at 50\% RH (S3) were larger than those when the absolute humidity was kept the same at $\mathrm{AH}=4.0 \mathrm{~g} / \mathrm{kair}$ (S2), suggesting formaldehyde emission at identical RH was more sensitive to temperature variation.
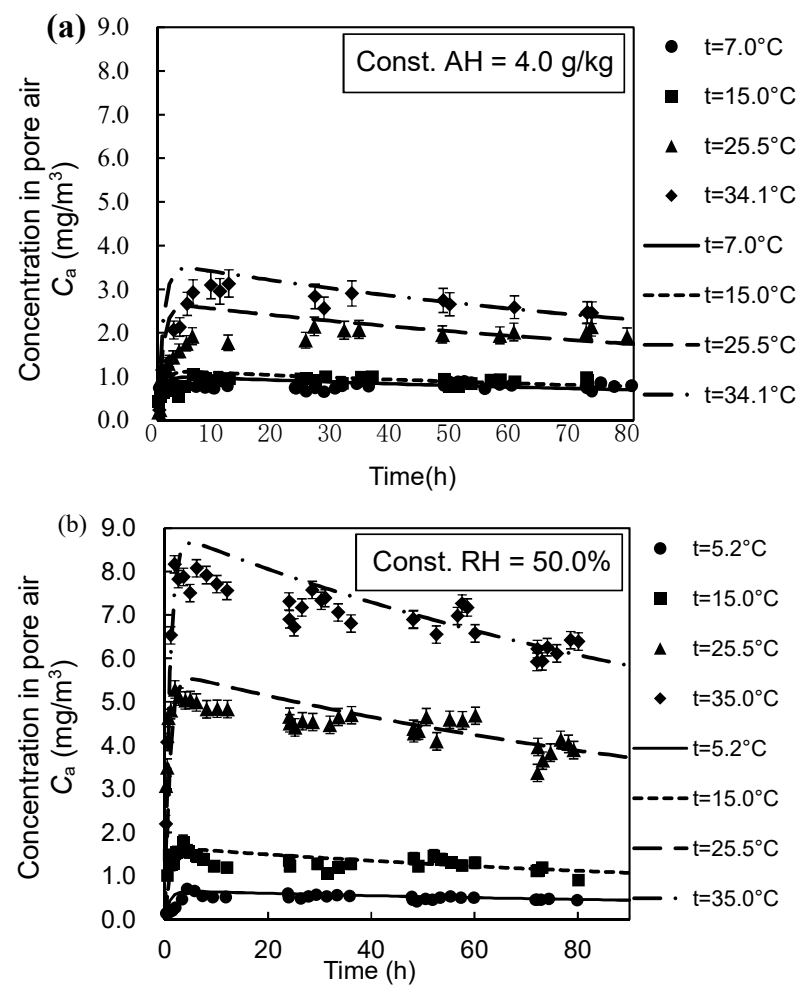

Fig. 5. Formaldehyde concentration in the chamber air with different temperature and humidity conditions. (a) measured results of S2 with same absolute humidity $(\mathrm{AH})$, (b) measured results of $\mathrm{S} 3$ with same relative humidity $(\mathrm{RH})$.

At the combined effects of temperature and $\mathrm{AH}$ as shown in Fig. 5 (b), the formaldehyde concentration increased more significantly than if only temperature increased. For instance, in series S3, average formaldehyde concentrations at $t=25.5{ }^{\circ} \mathrm{C}, \mathrm{AH}=10.4$ $\mathrm{g} / \mathrm{kg}_{\text {air }}$ were about 3.4 times higher than that at $t=15.0^{\circ} \mathrm{C}$, $\mathrm{AH}=5.2 \mathrm{~g} / \mathrm{kg}_{\text {air. }}$ In series S2, Fig. 1 (a) when temperature 
was increased without affecting $\mathrm{AH}$, the average formaldehyde concentrations at $t=25.5^{\circ} \mathrm{C}, \mathrm{AH}=4.0 \mathrm{~g} / \mathrm{kg}$ air were about twice as high as the concentrations at $t=15.0^{\circ} \mathrm{C}, \mathrm{AH}=4.1 \mathrm{~g} / \mathrm{kg}_{\text {air. }}$.

From the measurement results on humidity effect studies, formaldehyde emission generally increased with humidity. When RH was kept the same (S3), AH increased with temperature, and thus the effects of $\mathrm{AH}$ and temperature on formaldehyde emission were coincident and altogether large. When $\mathrm{AH}$ was kept constant (S2), RH decreased as temperature increased, so the effects of $\mathrm{RH}$ and temperature on formaldehyde emission were opposite to each other. The increase of formaldehyde emissions were much larger in S3 than S2.

\section{Determination of the diffusion similarity factors}

\subsection{Evaluation of CHAMPS-BES data}

In Section 2.1, the hypothesis was established that the diffusion similarity factor should depend on the physical / chemical properties of the VOC molecules. Evaluation of the VOC database content of the CHAMPS-BES software shows that it decreases linearly with the logarithm of the partition coefficient (Fig. 6). It can be concluded that higher partition coefficients correspond with higher VOC concentrations absorbed by the material, i.e. the apparent diffusion resistance decreases with higher VOC concentration due to diffusion "shortcuts" created by absorbed VOC islands.

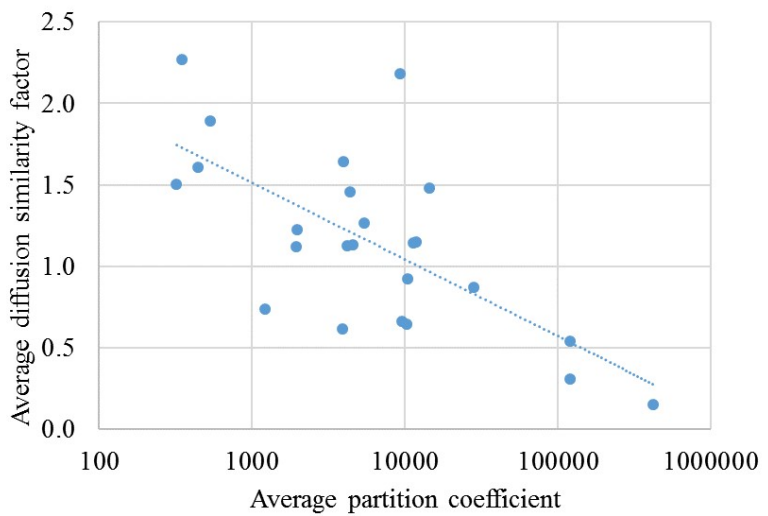

Fig. 6. Analysis of the VOC database content of the CHAMPSBES software (unreferenced data). Each point represents a VOC-material combination.

\subsection{Evaluation of diffusion coefficients from literature}

Using data from [7], provided as part of the Annex 68 ST2 work, apparent diffusion coefficients $D_{m}$ and partition coefficients $K_{m a}$ with respective references could be analysed for different $\mathrm{VOC} /$ material combinations.

The data from [7] includes measurements from [8] in which dual chamber experiments were conducted to measure diffusion through identical Calcium Silicate samples. The measurements in [8] were carried out for water vapour and six different VOCs. Some of the measurements were replicated. A $\mu_{d r y}$-value of 8.75 was reported for water vapour, which is in good agreement with the cluster average of 6.5 (see cluster definition below in the following paragraphs). The measured $\mu_{v o c}$ values of the VOCs were in the same order of magnitude (1.5-4.5).

In a first step, all material / VOC combinations were plotted together in one graph, which led to a large scatter as displayed in Fig. 7. Nevertheless, some first conclusions can be drawn: It was clear that the data should be separately analysed for each material, and data should be represented on $\log _{10}$ scales in order to see effects.

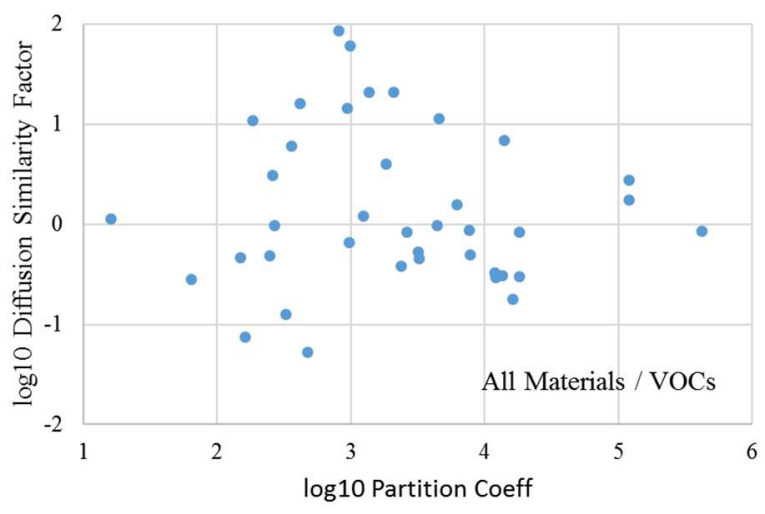

Fig. 7. Graphical analysis of VOC-material data by [7] and [8].

The subsequent data analysis comprised the steps:

1. Calculation of the effective diffusion coefficient $D_{e}=D_{m} \cdot K_{m a}$,

2. Calculation of the diffusion resistance factor $\mu_{v o c}=D_{v o c, a i r}\left(23^{\circ} \mathrm{C}\right) / D_{e}$ by using the trend equation displayed in Fig. 1 above,

3. Calculation of the diffusion similarity factor $\kappa_{d i f f, v o c}=\mu_{v o c} / \mu_{d r y}$ by using the dry cup value.

In order to get the correct values for $\mu_{d r y}$ (step 3), the respective material used for VOC measurements must be identified in the material database of DELPHIN6. Except for Calcium silicate, the materials were just referenced by name, which makes their identification very complicated. Since no further material parameters were provided with the materials, $\mu_{d r y}$ must be regarded as uncertain. In the future, some additional building physical properties should be measured along with the VOC diffusion experiments. This would greatly help to identify the correct material to derive the respective $\mu_{d r y}$.

In order to circumvent the problem in the short term, all materials were collected in the DELPHIN6 database with names that indicate similar material types, and cluster mean values were defined, which were used as initial estimates for the vapour diffusion resistances. This leaves an inherent uncertainty that leads to a possible vertical shift of the graphs in Fig. 8 - Fig. 10.

All graphs show relations that follow the initially supposed trend indicated in Fig. 6. It can be concluded that the diffusion similarity factor systematically decreases with increasing partition coefficient and that the slope of the curves depends on certain material properties. Until now, it has not been investigated, which material property could be a candidate to predict the slope of the diffusion similarity factor function. 


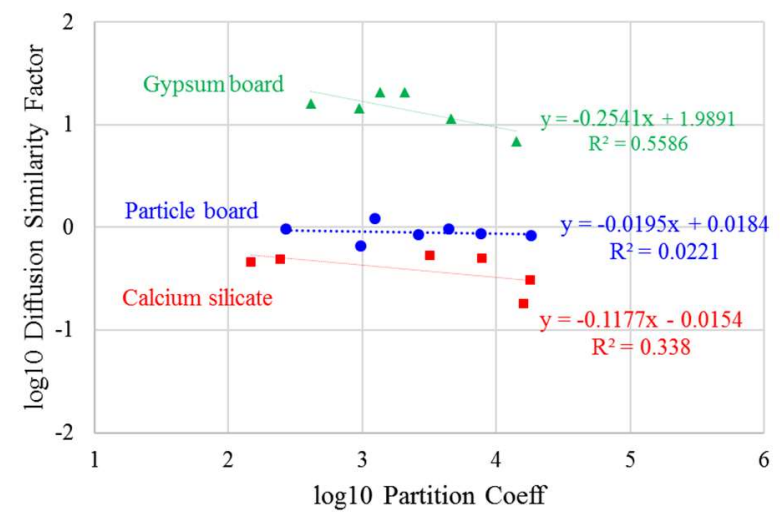

Fig. 8. Diffusion similarity factors of gypsum board, particle board and calcium silicate.

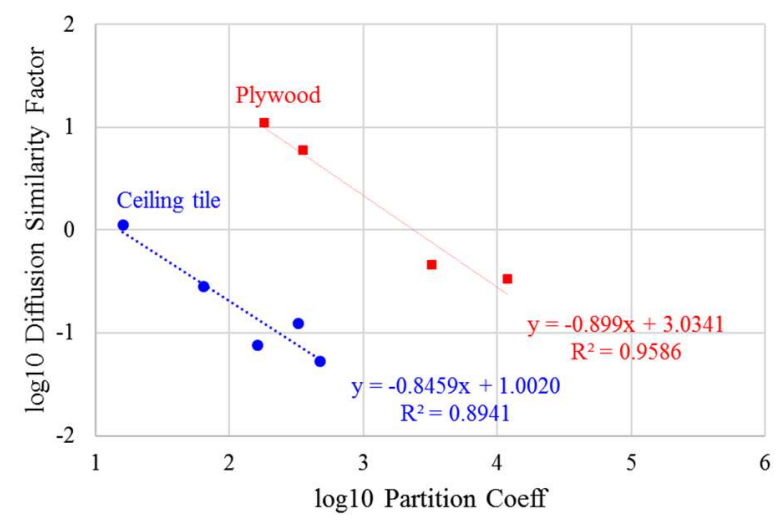

Fig. 9. Diffusion similarity factors of plywood and ceiling tile.

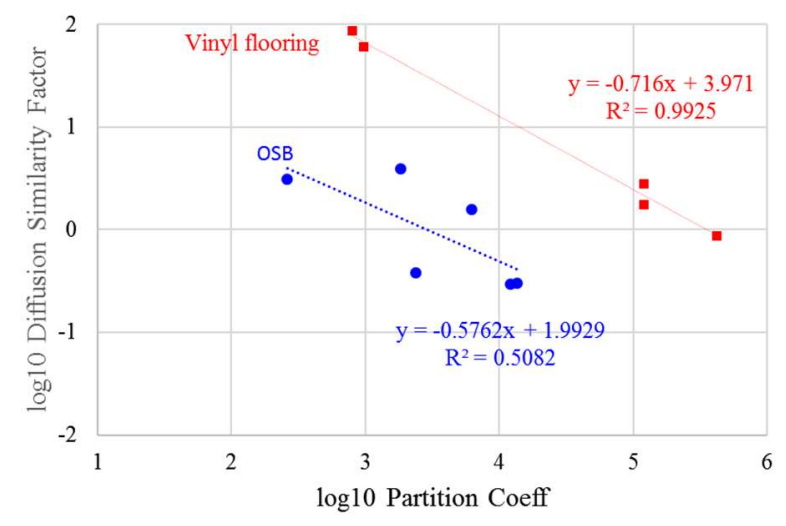

Fig. 10. Diffusion similarity factors of vinyl flooring and OSB.

\section{Simulation of VOC emission under non-isothermal conditions}

To test the newly implemented VOC model in DELPHIN6 together with the derived diffusion similarity relations, a test series was created that continues the Annex 68 ST3 common exercise with the PASSYS cell. For this purpose, an initial condition of $30,000 \mathrm{mg} / \mathrm{m}^{3}$ hexanal was introduced into the bottom plate of the test space consisting of PS foam and the emission from the material into the interior air of the test room is simulated. In order to allow the VOC to escape, the steel plating was removed so that the PS foam has direct contact with the air. The investigated effects were, on the one hand, the fixed mass balance of the VOC (no VOC can leave the PASSYS cell), and on the other hand the temporal course of the emission. Different cases were compared (air exchange vs. no air exchange, and isothermal vs. nonisothermal conditions).

The setup of the PASSYS cell for the non-isothermal test cases is shown in Fig. 11. Boundary conditions were assigned with an external air temperature of $20^{\circ} \mathrm{C}$ and ground temperatures of 0,20 and $40^{\circ} \mathrm{C}$. The high and low ground temperatures were chosen to accelerate, respectively decrease, emissions from the material.

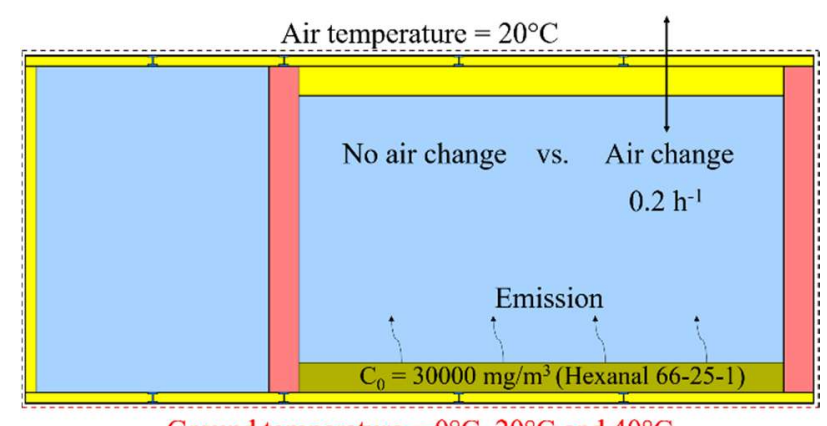

Ground temperature $=0{ }^{\circ} \mathrm{C}, 20^{\circ} \mathrm{C}$ and $40^{\circ} \mathrm{C}$

Fig. 11. Construction setup of the PASSYS cell for nonisothermal test cases.

Fig. 12 shows the temperature fields after 20 days for both $0^{\circ} \mathrm{C}$ and $40^{\circ} \mathrm{C}$ ground temperatures. It can be seen that the air change with $20^{\circ} \mathrm{C}$ external air temperature has the expected impact on the room air temperatures.

As also shown in Fig. 12, there is a clear temperature effect: higher temperatures generate larger emission rates and higher equilibrium concentrations in the room air. The results are consistent with the experimental results shown in Fig. 5. The effects can be traced back to the balance equation model for VOCs implemented in DELPHIN6 that contains a phase transition term that communicates between the mass balances in the gas phase and the absorbed phase. The key idea of the immobilemobile phase model is, that the actual gas phase concentration may deviate from the temperature dependent equilibrium concentration. It will, however, in time approach the equilibrium concentration. This is modelled by defining the phase transition mass source/sink based on the difference between actual and equilibrium gas phase concentration.

In summary, the tests provided insight into the capabilities of the new VOC model implemented in DELPHIN6. All tests were successful and the results were in line with expectations. Further model features may be required, such as the implementation of a time-dependent VOC sink or source, which may be applied, for example, in indoor air. In addition, complete coupling to the hygrothermal simulation has still not been finished, and the airflow network cannot be used together with the VOC mass balance. These challenges are to be addressed in future developments and implementations. 
No Air change

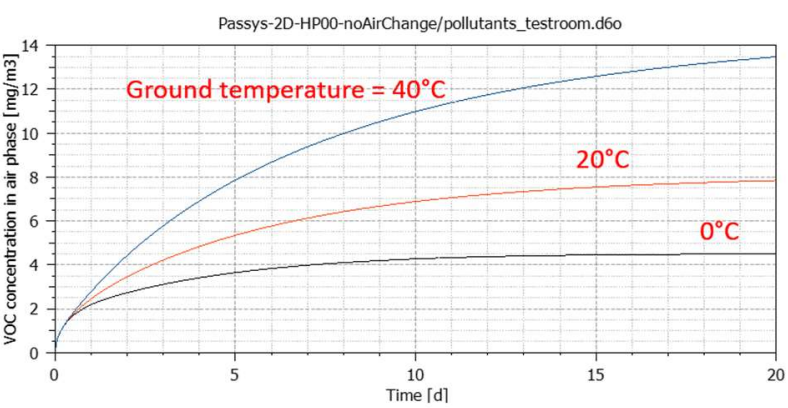

Passys-2D-HP00-noAirChange - Temperature
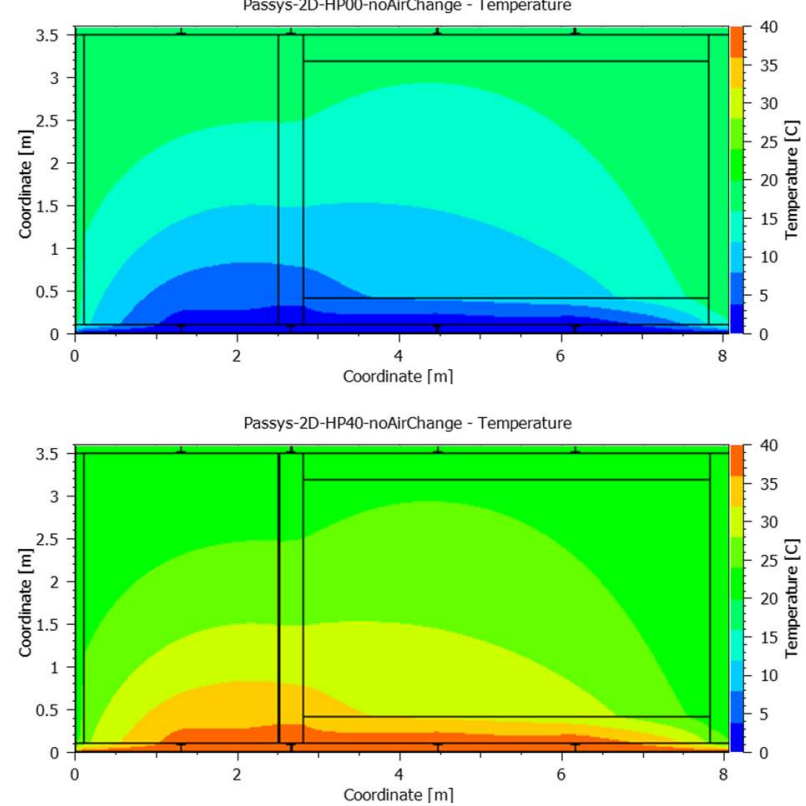

Air change

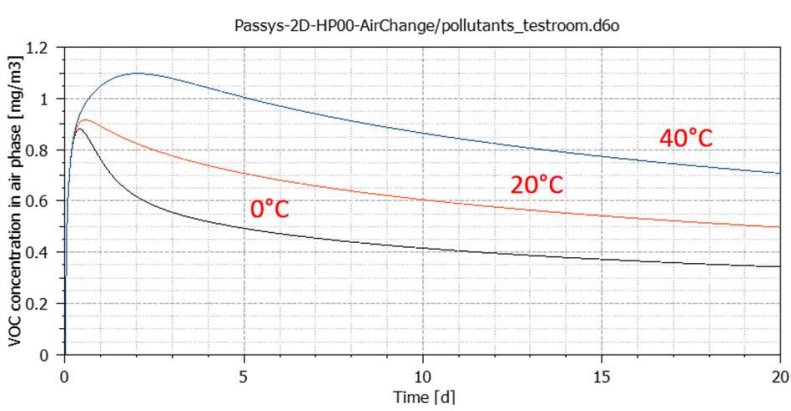

Passys-2D-HP00-AirChange - Temperature
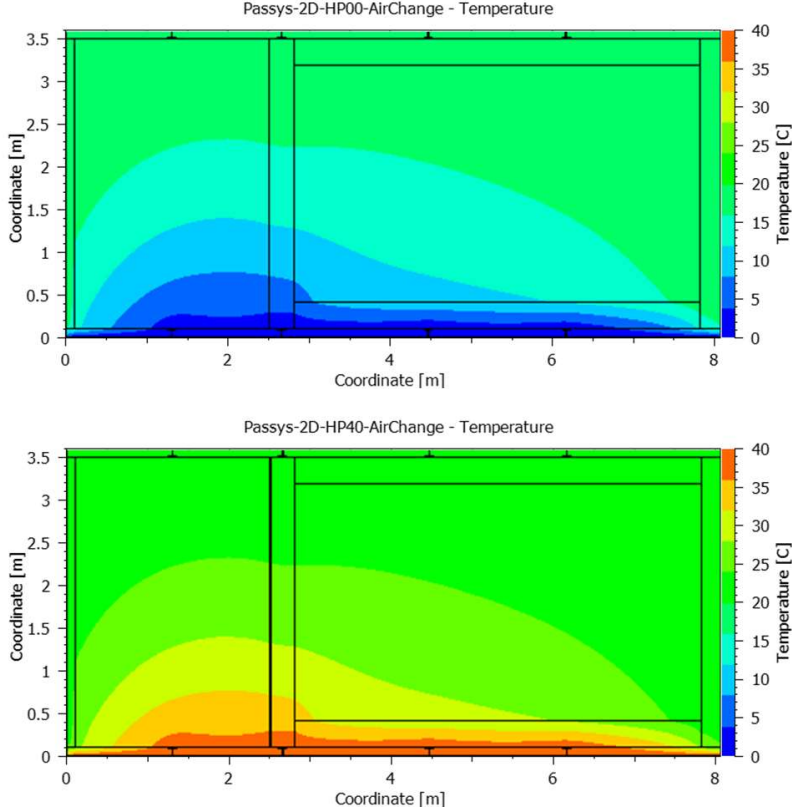

Fig. 12. VOC concentration in the PASSYS test room with and without air change for three different ground temperatures (top left and right) and temperature fields for $0^{\circ} \mathrm{C}$ and $40^{\circ} \mathrm{C}$ ground temperature after 20 days (middle and bottom left and right).

\section{Conclusions and outlook}

Based on similarity approaches with regards to material properties and model paradigms for moisture and VOC transport it is possible to achieve advances in the assessment of integrated heat, air, moisture and pollutant distributions in materials and for whole buildings. The concepts permit also to consider some mutual influences between temperature and humidity on emissions. The paper has demonstrated such developments and analyses, which have been further elaborated in the IEA EBC Annex 68 project.

The perspective is that this knowledge can be brought into tools for design and operation of buildings so their need for ventilation can be better optimized, e.g. according to demand. The aspiration is that this can contribute to both to achieving better indoor environments and more energy efficient building operation.

\section{References}

1. L.C.R. Salis, M. Abadie, P. Wargocki, C. Rode, enbuild, 152 402-502 (2017)

2. H.S.L.C. Hens, EBC Annex 41 Project Summary Report, AECOM Ltd (2013)

3. J. Zhang. http://champs.syr.edu/index.html. (2010).
4. J. Grunewald, Diffusiver und konvektiver Stoff und Energietransport in kapillarporösen Baustoffen (dissertation). Dresdener Universität (1997)

5. M. Jischa, Konvektiver Impuls-, Wärme- und Stoffaustausch. Springer (1982)

6. K. Stephan, F. Mayinger, Thermodynamik. Bd 2: Mehrstoffsysteme und chemische Reaktionen. (Stichworte Teil 1). Springer (1988)

7. A. Nicolai et al. Recent improvements in HAM simulation tools: Delphin 5/CHAMPS-BES. 12th Symposium on Building Physics, Dresden (2007)

8. R. Schirmer, Die Diffusionszahl von WasserdampfLuft-Gemischen und die Verdampfungsgeschwindigkeit, VDI-Verlag (1938)

9. M.J. Tang, M. Shiraiwa, U. Pöschl, R.A. Cox, and M. Kalberer, Atmos.Chem.Phys., 15 5585-5598, (2015)

10. Z. Liu et al. Development of a Procedure for Estimating the Parameters of Mechanistic Emission Source Models from Chamber Testing Data. in $7^{\text {th }}$ International Building Physics Conference (2018)

11. J. Xu, Study of VOCs transport and storage in porous media and assemblies, in Mechanical and Aerospace Engineering, Syracuse University (2012)

12. A. S. Bodalal. Fundamental mass transfer modeling of emission of volatile organic compounds from building materials. PhD thesis, (1999) 